\title{
Pautas de reforma del Estado en la Europa post-socialista
}

\author{
José M. Ruano de la Fuente *
}

\section{Consideraciones previas}

Las nociones de autonomía local y regional pertenecen en nuestros días al primer plano de la actualidad institucional. Suelen evocarse como las soluciones más acertadas para hacer frente a lo que bien podría denominarse la crisis de las formas tradicionales de organización del Estado, al tiempo que se presenta a los modelos de descentralización de los países de Europa central y oriental como premisas para la democratización de sus sistemas políticos. Por otra parte, la Carta Europea de la Autonomía Local y Regional, en vigor desde el primero de septiembre de 1988, ha sido firmada, a partir de 1995, por 24 países, lo que constituye, dicho sea de paso, una de las puertas de entrada al Consejo de Europa.

Por su parte, el Tratado de Maastricht ha supuesto una suerte de reconocimiento oficial de las entidades territoriales a través de la creación del Comité de las Regiones y de las Colectividades Locales, de la misma manera que la puesta en primer plano del principio de subsidiariedad, consagrado en el mismo Tratado de la Unión Europea, ha contribuido a relanzar las ideas favorables a la descentralización del poder y se ha erigido en uno de los requisitos de acceso al club comunitario.

Además, la presencia y la fuerza renovada de las ideas descentralizadoras en Europa occidental son el modelo de referencia de los países de Europa central y oriental y el medio para la vigorización de los procesos de transformación de las estructuras heredadas de los regímenes del llamado «socialismo real» en un cuerpo político-institucional acorde con los parámetros de la Europa occidental, basados en la democracia política y la descentralización del poder estatal en favor de entidades territoriales autónomas. Y es, precisamente, la Carta Europea de la Administración Local y Regional, ya referida, el documento inspirador de los constituyentes y legisladores de los países post-socialistas, pese a lo cual en ninguno de estos países la reforma de la estructura territorial del Estado parece haber alcanzado su necesario punto de equilibrio. Junto a una nueva vitalidad experimentada en los centros políticos regionales y locales, permanecen serias incertidumbres acerca del nivel competencial y del papel que debe corresponder al Estado en el nuevo escenario resultante del ahondamiento en el reparto del poder entre instituciones políticas de ámbito territorial. A pesar de tratarse de países con características y circunstancias políticas en cierto grado comunes, la situación parece bastante diferente de unos a otros: mientras que algunos países presentan procesos de descentralización semejantes a los propios de Europa occidental (Hungría, Polonia, República Checa, Eslovaquia, Letonia), en otros los nuevos entes descentralizados no han hecho más que echar a andar y, consecuentemente, su funcionamiento resulta, cuanto menos, incierto (Albania, Estonia, Lituania, Rumania).

Una vez presentada la estructura institucional de los diferentes países considerados, se analizan brevemente los diferentes modelos de financiación y gestión de las competencias de los entes descentralizados, con la finalidad de extraer conclusiones a partir del establecimiento de comparaciones con la realidad de los países occidentales, que, como ha quedado ya puesto de manifiesto, sirven de referente a estos países en tran- 
sición política, pero también institucional. Por último, una vez contemplada en su globalidad la nueva ordenación territorial de los países considerados, se analiza el proceso interno de reforma de sus Administraciones estatales y se ofrecen algunas razones que pueden contribuir a explicar su relativo fracaso. Para todo ello, se ha considerado la situación política y administrativa de Bulgaria, Hungría, Eslovenia, Croacia, Polonia, República Checa, Rumania, Eslovaquia, Albania y los países bálticos ${ }^{1}$. Se ha contemplado también, aunque necesariamente desde otra perspectiva, la especialísima situación de la antigua República Democrática Alemana tras su integración en la República Federal, y se ha excluido conscientemente la consideración de Yugoslavia, Macedonia y Bosnia-Herzegovina por ofrecer un grado considerable de incertidumbre e inmadurez política e institucional que no permite realizar comparaciones válidas en esta materia.

\section{Los niveles de descentralización política y administrativa}

\section{A. La estructura político-administrativa de los países del Este de Europa}

Conviene tener en cuenta, antes de proceder a describir las grandes líneas de la estructura administrativa de los países del Este de Europa, que los procesos de descentralización están intimamente ligados a una finalidad muy concreta: la definitiva afirmación de la democracia, lo que quizá contribuya a explicar el porqué de la fragmentación municipal que puede observarse en alguno de estos países.

En los regímenes socialistas, la Administración local y regional estaba fundada sobre la doctrina de la unidad del poder formulada por Lenin, que encontró su primera expresión en el sistema de los soviets, generalizado desde la finalización de la segunda guerra mundial en todos los países de Europa central y oriental, y según el cual los consejos regionales y locales no formaban parte de una Administración descentralizada, sino que eran meros órganos desconcentrados del poder Estado para la ejecución de sus iniciativas políticas. Debían tomar en consideración las diferentes condiciones locales o regionales, pero sin poner en tela de juicio la identidad de intereses entre el Estado y los entes de ámbito territorial inferior. Esta forma de integración quedaba asegurada, desde un punto de vista formal, por el principio de la doble subordinación, en el que se veía una de las manifestaciones del centralismo democrático.
En virtud de este principio, los ejecutivos locales y regionales eran responsables simultáneamente ante los consejos que formalmente les habían elegido y ante los ejecutivos de nivel superior. De esta forma, los consejos territoriales quedaban constituidos como meros agentes del poder central para la puesta en práctica de las políticas generales del Estado. La Administración regional o local disponía, también formalmente, de numerosas competencias sobre las más diversas materias, pero eran ejercidas sin ningún margen de autonomía, en función de las directrices emanadas del poder central y con medios financieros condicionados.

Así, en este momento deben observarse las instituciones subnacionales de estos países como partes subordinadas de una estructura burocrática y administrativa centralizada. Los dirigentes locales eran designados por el partido y su actuación política quedaba, por ello, supeditada a un doble sistema de control: a la Administración periférica de los ministerios, desplegada en el nivel territorial regional o local y, en última instancia, al partido comunista residenciado en el centro político. El papel de los miembros de los consejos locales se reducía a la aplicación de los planes de desarrollo económico y social, a ejecutar el presupuesto asignado por el centro y a designar a los componentes de los variados comités responsables de la prestación de servicios municipales o supramunicipales. Hay que hablar, por tanto, de un sistema fuertemente centralizado y jerarquizado a varios niveles (el del comité, el municipal, el distrital o del condado y, en su caso, el regional), cuya unidad de actuación quedaba garantizada por la autoridad del partido, que atravesaba todos estos centros de poder.

Desde un punto de vista presupuestario, este sistema conducía necesariamente a la integración de los presupuestos regionales y locales en el presupuesto del Estado, lo que se traducía en el establecimiento de prioridades anuales, en función de las que se atribuían a las autoridades territoriales los medios planificados en que cristalizaban sus correspondientes presupuestos, finalmente votados en los consejos territoriales sobre la base de los medios financieros otorgados por el Estado. En consecuencia, el presupuesto de las entidades regionales y locales era el producto de una desagregación de los diferentes presupuestos ministeriales para aquellas funciones que tenían que gestionarse a nivel local o regional. Sin embargo, las autoridades de los entes formalmente descentralizados tan sólo eran ejecutantes del presupuesto general del Estado y los agentes de sus departamentos ministeriales.

Sólo ahora quizá pueda comprenderse por qué los procesos de descentralización política y administrativa en los países ex-socialistas comportan ineluctablemente una reforma profunda de las instituciones y de las formas de gestión tradicionalmente empleadas en los regímenes políticos anteriores ${ }^{2}$. 


\section{B. Las nuevas instituciones locales}

Salvo en los casos de Bulgaria y de Lituania, pronto el cambio de régimen político se tradujo en el plano local en una viva reacción contra el funcionalismo que había inspirado las reformas territoriales de los años sesenta y setenta, y contra el nivel intermedio de administración, auténtico multiplicador del poder estatal. El nivel municipal es hoy el único nivel de descentralización en la práctica totalidad de los países, mientras que tan sólo puede hablarse de la incipiente existencia de entidades descentralizadas de nivel supramunicipal en Letonia. La razón principal parece haber sido el propósito de que la democracia arraigase en los municipios, que debían ser la base de un nuevo sistema de democracia local fundado sobre el principio de autonomía, en tanto que los niveles superiores eran contemplados con profunda desconfianza a causa de su importancia y el papel que les atribuyó el régimen político anterior, por lo que han sido suprimidos.

En efecto, éste es el caso de las regiones en Polonia, Chequia y Eslovaquia, que han sido reducidas a una simple división administrativa al servicio de la Administración del Estado. En el caso de estos dos últimos países, tras la abolición del sistema de comités nacionales y la restauración de entidades municipales autónomas, la desconcentración de funciones del Estado se adoptó como una solución temporal hasta que se creasen las regiones previstas en sus respectivas Constituciones. Este proceso de desconcentración debía permitir a la Administración estatal continuar ejerciendo su control de las actuaciones de los nuevos municipios democráticos en ámbitos territoriales cercanos a éstos (los distritos). La supresión del sistema de organización socialista del territorio comportaba, de otro modo, la separación, la desconexión, entre el centro político y la periferia en un nivel territorial intermedio. Nos encontramos en el momento de transición en que han sido abolidas las instituciones socialistas sin ser plenamente sustituidas por las previstas en las nuevas Constituciones. En este sentido, puede advertirse fácilmente cómo, paradójicamente, los procesos de descentralización política van acompañados de iniciativas de desconcentración por parte de una Administración central acostumbrada tradicionalmente a ejercer un fuerte control de las instituciones subnacionales desde antes incluso de la segunda guerra mundial, favorecido este fenómeno, como se verá más adelante, por la debilidad de los entes locales y la inestabilidad del sistema político general ${ }^{3}$.

En todos los casos, no obstante, el sentido de la reforma no fue siempre la misma. En Polonia se quiso evitar una competencia que habría perjudicado a los municipios. La ocupación extranjera de Polonia desde finales del siglo xvm por Rusia, Prusia y Austria parece traducirse en diferentes tradiciones de gobierno local. Así, coexiste una fuerte tradición liberal de autogobierno local en el sur del país que perteneció al imperio aus- trohúngaro con las reminiscencias del sistema prefectoral de inspiración francesa propio del Estado polaco de entreguerras. $\mathrm{La}$ ambivalencia entre la conservación de las instituciones propias del centralismo socialista y la reemergencia de estructuras de gobierno regional y local autónomas se constituyó en un freno al proceso de democratización del país. Tras un lapso de transición en el que las antiguas 49 regiones (vojevodships) actuaban como ámbitos de desconcentración del Estado, la reforma del Estado polaco de 1 de enero de 1999 trata de compatibilizar un cierto grado de control del centro político con la existencia de instituciones subnacionales de autogobierno (16 regiones y 373 condados) de referente histórico, competencias y subsistencia presupuestaria dudosas. En Lituania, una profunda reforma de la Administración local que tuvo lugar en 1994 suprimió 55 entidades locales de segundo nivel y se procedió a dividir el país en solamente 10 entidades (apskritis) administradas por gobernadores designados por el Estado, algunas de cuyas funciones correspondían anteriormente a los municipios. En cambio, las provincias rumanas (judets) han visto incrementar su número de funciones, sea esto el reflejo de que el proceso de reforma es menos avanzado en este país, sea porque se haya aprovechado esta división territorial para potenciarla bajo la forma de corporaciones territoriales descentralizadas.

Por su parte, en Hungría, al tiempo que las Administraciones locales de segundo grado se han conservado tras el compromiso alcanzado entre los partidarios y contrarios a su supresión, pero con funciones en la mayoría de los casos subordinadas a las municipales, la construcción institucional del país se ha visto fuertemente condicionada por los avatares políticos y los sucesivos cambios de gobierno. Así, mientras que en 1990 se dividió el país en 8 regiones con el carácter de circunscripciones administrativas del Estado, el acceso al poder cuatro años después de una coalición de centro-izquierda formada por los excomunistas del partido socialista y el partido liberal tuvo como con. secuencia la desaparición de las regiones y la configuración del nuevo Estado con base en unidades desconcentradas del Estado y entidades locales autónomas reforzadas política y funcionalmente. Desde septiembre de 1996, los proyectos de reforma institucional del Estado húngaro tienen su inspiración, como los de la mayoría de los países post-socialistas que estamos analizando, en las exigencias y el cuerpo normativo de la Unión Europea y del Consejo de Europa, en especial, en la Carta Europea de la Autonomía Local.

Especial significación ha tenido el proceso de reforma ins titucional de Alemania oriental. La unión de los Estados alemanes revistió la forma de una aceptación del ordenamiento jurídico y de la organización territorial de la República Federal. La estructura política de la antigua $\mathrm{RDA}$ fue disuelta en octubre de 1990 y, al igual que ocurrió en otros países ex-socialistas, aquellas instituciones que se indentificaban especialmente con 


\begin{tabular}{|c|c|c|c|}
\hline & Tabl & itoriales & \\
\hline Regiones & A. $L$. & $2 .^{\circ}$ grado & Nivel municipal \\
\hline Albania & & 36 prethet & 361 \\
\hline Bulgaria & 9 oblasti & & 255 \\
\hline Croacia & & 20 zupanije & 489 \\
\hline Chequia & $13 \mathrm{kraj}$ & 76 okres & $6.231_{5}^{4}$ \\
\hline Eslovaquia & $8 \mathrm{kraj}$ & 79 okres & $2.858^{5}$ \\
\hline Eslovenia & & & 147 \\
\hline Estonia & & 15 maakonds & $255^{6}$ \\
\hline Hungría & & 19 megye & $3.282^{7}$ \\
\hline Letonia & & 26 rajons & $4.634^{8}$ \\
\hline Lituania & & 10 apskritis & 56 \\
\hline Polonia & 16 vojevodships & 373 poviats & $2.489^{9}$ \\
\hline Rumania & & 41 judets & 2.951 \\
\hline
\end{tabular}

Fuente: Elaboración propia a partir de datos de SIGMA y del Consejo de Europa. Sólo las divisiones territoriales en negrita son Administraciones autónomas descentralizadas. El resto son divisiones administrativas del Estado.

el anterior régimen y desempeñaban un importante papel en él fueron abolidas. Es el caso de los distritos administrativos (Bezirksregierungen) que desde 1952 habían reemplazado a los cinco Länder en que se dividía el país, ahora recuperados. Poco después, el pequeño tamaño de los cerca de 15.000 municipios (Gemeinden) de la antigua Alemania socialista obligó a las autoridades federales a recurrir a otro nivel administrativo (denominadas Ämter en Brandeburgo y Mecklemburgo-Pomerania occidental) que sirviera de motor asistencial de los inframunicipios.

La reforma de la Administración local en Europa central y oriental ha adquirido la forma de una restauración de municipios como reacción frente a las fusiones impuestas durante el régimen anterior por parte del poder central. Si bien el número de municipios venía reduciéndose paulatinamente desde los años cincuenta debido a las reformas administrativas y de urbanización que concluyen en las fusiones de los años sesenta y setenta en toda Europa central y oriental, el hundimiento de los regímenes socialistas coincidió con un fuerte impulso democratizador de las instituciones más cercanas a los ciudadanos de la mano de la recuperación de su autonomía por parte de pequeñas corporaciones. La intensidad, sin embargo, de este fenómeno de fragmentación municipal no es la misma en todos los países. Mientras que en Polonia se tradujo en un aumento de cerca del $4 \%$ en el número de municipios, Eslovaquia superó ese porcentaje y los municipios checos se incrementaron en un más de un $51 \%$ en menos de cinco años de democracia local. Así, puede afirmarse que, salvo en Bulgaria y Lituania, el número de municipios resulta excesivamente elevado y que éste ha aumentado considerablemente desde los primeros años de la caída de los regímenes socialistas. En Polonia el número de municipios pasó de 2.375 en 1991 a 2.468 a comienzos de 1994. Chequia, por su parte, contaba con 6.196 a finales de 1993 en lugar de los 4.092 de finales de los años ochenta. La misma evolución puede observarse en Eslovaquia, donde el número de municipios ha pasado de 2.725 a 2.853 en el mismo período. En Rumania el asesinato de Ceaucescu prácticamente coincidió con el abandono de los planes de «sistematización» adoptado desde finales de los años sesenta, que suponían el agrupamiento de la población en localidades jerarquizadas funcionalmente por el poder central y la destrucción de los núcleos abandonados.

Tan sólo Lituania ha emprendido una reforma radical de la Administración local desde una perspectiva funcional, reemplazando un sistema de dos grados, que comprendía 55 distritos y 258 unidades municipales de estatutos y dimensiones diversos, por un sistema de descentralización basado únicamente en 56 municipios como corporaciones descentralizadas, de población y superficie semejantes, y agrupadas en 10 circunscripciones como unidades desconcentradas del Estado.

Las causas de esta súbita fragmentación municipal hay que buscarlas en factores diversos relacionados entre sí. Observando con detenimiento la curiosa crónica de los primeros momentos de democratización de las corporaciones locales en tres de los países que aquí consideramos que nos ofrece Wisla SURAzKA ${ }^{10}$, parece que la ilusión de los primeros momentos ante el cambio de régimen, el sentimiento de abandono, las diferencias entre el mundo urbano y rural, la reacción frente a las funciones forzosas durante el régimen socialista y, en menor medida, las diferencias étnicas entre localidades, son factores que en gran medida están en el origen de este proceso de descomposición de los sistemas locales anteriores, contemplados como condición necesaria de la revitalización democrática del nivel municipal.

La búsqueda de las raíces locales constituye lo que WEBER llama los «intereses ideales» de los actores locales. Pero también cabe identificar en este fenómeno sus intereses materiales. En este sentido, la transferencia del patrimonio del Estado a las nacientes Administraciones locales y la privatización de inmuebles, tierras y empresas pueden haber actuado como impulso de ese renovado interés de la ciudadanía por los asuntos locales. Además, la relación entre la existencia de una ciudadanía activa y la autonomía local, como ya observó TOCQUEVILLE, se confirma claramente en este caso.

Si esta evolución parece muy positiva como factor de desarrollo democrático, sus consecuencias desde el punto de vista de la gestión son mucho más sombrías. En efecto, nos encontramos aquí con un fenómeno que resulta familiar a los habitantes de países mediterráneos: el inframunicipalismo (ver Tabla 2). El alto número de municipios de pequeño tamaño tiene como consecuencia más inmediata, pasados los primeros fervores de la democracia recuperada, la existencia de entidades con dificultades financieras, estrechísimo margen de maniobra para la contratación de personal cualificado y para la prestación de servicios de mediana complejidad ${ }^{11}$. 


\section{Tabla 2}

Población, extensión y tamaño medio municipal

\begin{tabular}{|lccc|}
\hline & $\begin{array}{c}\text { Población } \\
\text { (en millones) }\end{array}$ & $\begin{array}{c}\text { Extensión } \\
\text { (en km²) }\end{array}$ & $\begin{array}{c}\text { Tamaño medio } \\
\text { municipal }\end{array}$ \\
\hline Albania & 3,3 & 28.748 & 9.141 \\
Alemania 0. & 17,7 & 108.500 & 1.195 \\
Bulgaria & 8,5 & 110.994 & 33.333 \\
Croucia & 4,7 & 56.638 & 9.611 \\
Checquia & 10,3 & 78.864 & 6.231 \\
Eslovaquia & 5,3 & 49.035 & 2.858 \\
Eslovenia & 2,0 & 20.256 & 13.605 \\
Estonia & 1,5 & 45.226 & 5.882 \\
Hungria & 10,4 & 93.033 & 3.160 \\
Letonia & 2,6 & 64.589 & 4.634 \\
Lituania & 3,8 & 65.300 & 67.857 \\
Polonia & 38,0 & 312.683 & 15.267 \\
Rumania & 23,5 & 237.500 & 2.951 \\
\hline
\end{tabular}

Fuente: Elabomaión propia.

Por otro lado, a pesar de este grado de fragmentación, el nivel de cooperación intermunicipal es escaso. El peso relativamente importante del Estado y el sostenimiento financiero de éste a proyectos municipales son factores que, sin duda, han favorecido este resultado, y pone sobre la mesa la cuestión del desarrollo de niveles regionales de descentralización amparada en razones puramente técnicas.

\section{La naturaleza política de las instituciones locales}

Desde 1990 cada uno de los países considerados presentan rasgos distintivos por lo referido a la configuración del marco de democracia local. Así como Polonia otorga un alto grado de discrecionalidad a las entidades locales desde una perspectiva gerencial, en otros países adquiere un mayor peso la Asamblea electa y, en otros casos, la responsabilidad recae de forma conjunta en ésta y el ejecutivo. Sin embargo, más allá de estas características diferenciadoras que son propias de la cultura política y de una tradición de autogobierno que se remonta a las primeras décadas del siglo, en términos generales resalta el trasvase de poderes de los órganos colegiados en favor del reforzamiento de los ejecutivos (algo que constituye ya una clara tendencia a las Administraciones, no sólo locales, de Europa occidental), y en el lugar preeminente de sus miembros.

La elección del órgano colegiado municipal se lleva a cabo mediante escrutinio plurinominal mayoritario en Eslovaquia, Chequia y los municipios rurales e intermedios de Polonia y Hungría; mediante sistema proporcional, en el resto de municipios de ambos países, Bulgaria, Albania y Letonia. Bajo formas diferentes, el ejecutivo local en los países bálticos es colegiado, mientras que, de una forma que puede resultar en algunos aspectos contradictoria, la afirmación del liderazgo del alcalde se apoya en la introducción de su elección mediante sufragio directo en Albania, Eslovaquia, Rumania y en los municipios de menos de 10.000 habitantes en Hungría (en el resto de los casos, el alcalde es elegido por el órgano colegiado del municipio). En Polonia, el órgano colegiado del municipio elige a su propio presidente, distinto de la figura del alcalde. En Eslovaquia y Hungría existe una forma de separación entre el liderazgo político, reconocido al alcalde, y la responsabilidad de los asuntos administrativos, cuya dirección se confía a un jefe de Administración elegido por el consejo del municipio, fórmula que recuerda claramente a la empleada en algunos de los Länder alemanes. Mayor capacidad de control administrativo sobre las Corporaciones locales, fruto en buena parte del menor desarrollo de los procesos de descentralización en estos países, se observa en Albania, donde el consejo municipal elige a los adjuntos al alcalde, o en Rumania, donde el jefe de la Administración es designado por el gobernador «provincial» (de los judets).

En la mayoría de los países la democracia política se acompaña de la introducción de instituciones de democracia directa a nivel local, tales como la obligatoriedad de recurrir al referendo antes de acometer determinadas materias (introducción de tasas coyunturales, la remodelación del ejecutivo municipal antes de agotar el mandato, la modificación del término municipal, etc.). Sin embargo, esta respuesta institucional a la demanda de democracia no tiene su correlato en la práctica política. Las instituciones de democracia directa son poco utilizadas y, para complicar aún más las cosas, la participación electoral en las elecciones locales es escasa (al igual que sucede, en términos relativos, en las democracias occidentales, por otro lado). En Polonia la participación ha bajado del 42,2\% de 1990 al 33,8\% de 1994; en Hungría permanece en torno al 50\%, al igual que en Eslovaquia ( $54 \%$ ) o en Bulgaria en las elecciones municipales de noviembre de 1995 (51\%). Solamente en Letonia, en mayo de 1994, la participación electoral alcañzó el 60\%.

Por otra parte, si se tiene en cuenta que las instituciones locales descansan en buena medida en la figura del alcalde, los jefes de la Administración y los órganos colegiados de los municipios, puede afirmarse que la influencia del poder central sigue siendo fuerte, toda vez que la presencia de los actores locales es débil y son incapaces de organizarse adecuadamente como grupos de presión frente al poder central. Un caso de asociación municipal que ha tomado forma de grupo de presión es el de la Unión de Ciudades y Municipios de la República Checa (UTVCR), asociación voluntaria dominada, sin embargo, por las grandes ciudades y que, como consecuencia de su composición, no representa los intereses de los municipios rurales.

No en vano, si bien las primeras elecciones locales, en 1990, lograron renovar en profundidad las estructuras municipales (entre un 70 y un $75 \%$ de los concejales), en un alto porcentaje los alcaldes han sido reclutados de entre antiguos responsables políticos o administrativos locales del régimen socialista (su 
renovación se sitúa entre el 40 y el $60 \%$ de los dirigentes locales). Estas magnitudes muestran, entre otras conclusiones, que la política local se asemeja en algunos países a la occidental, al menos por lo que se refiere a la nacionalización de la política local y, en este sentido, a la determinación de los acontecimientos políticos locales por los asuntos de ámbito estatal. Será preciso, en todo caso, realizar análisis más profundos que éste para poder evaluar la representatividad y verificar, en su caso, en qué medida esta evolución puede constatarse en otros países de la región.

\section{Los niveles intermedios de descentralización: Administraciones locales de segundo grado y Administración regional}

Es en el nivel supramunicipal donde las diferencias entre los distintos países resultan más patentes. Ahora bien, las estructuras actuales parecen provisionales en la mayoría de los casos. La cuestión acerca de la conveniencia de desarrollar niveles administrativos descentralizados de ámbito territorial superior al municipio es un tema abierto de gran actualidad, debido a la existencia de competencias de ámbito excesivamente amplio como para poder ser confiadas a los entes municipales.

Actualmente, sólo puede hablarse de Corporaciones locales descentralizadas supramunicipales en Polonia, de nivel regional y de condado, y en Letonia. En Hungría y Rumania, el comitat y el judet, respectivamente, pueden compararse a una comarca y a una provincia. En ambos casos puede distinguirse un consejo (en el caso de judet, elegido mediante sufragio indirecto), que elige, a su vez, a un ejecutivo que se encuentra fuertemente subordinado a la Administración estatal. En el resto de países no cabe hablar de entidades descentralizadas, sino de divisiones administrativas al servicio de la Administración periférica del Estado, sean de ámbito equivalente al provincial (Lituania, Estonia, Croacia, Albania) o infraprovincial (Chequia y Eslovaquia).

La región como Administración descentralizada no existe en ninguno de los países aquí considerados, si exceptuamos, a pesar de su reciente creación, a los vojevodships polacos. Sin embargo, la creación de niveles regionales descentralizados es un tema de gran actualidad política al menos en Hungría, Rumania y Eslovaquia, donde una Ley de julio de 1996, Llevando a efecto la previsión de la Constitución de enero de 1993, dividió el país en ocho regiones que hasta el momento sirven de circunscripción territorial de la Administración del Estado, pero cuyo futuro como nivel de gobierno autónomo resulta incierto. También la Constitución de diciembre de 1992 de la República Checa previó la creación de «entidades autónomas superiores» que, de acuerdo con la Ley de diciembre de 1997, deben empezar a ser una realidad a partir del año 2000 . Resulta chocante que precisamente en estos dos países fuese la supresión de las ya existentes una de las primeras medidas adoptadas inmediatamente después de la caída del régimen socialista para favorecer, precisamente, la centralización del Estado y garantizar, de este modo, su papel nodular en la transición al capitalismo y la democracia liberal. En cambio, hay divisiones de ámbito regional puramente administrativas en Bulgaria, dirigidas por un gobernador designado por el Consejo de Ministros. Hungria, por su parte, suprimió en 1994 la figura de los comisarios regionales, reemplazándolos por gabinetes de Administración pública diseñados para asegurar el cumplimiento de las directrices de la Administración estatal a nivel del comitat (de nivel equivalente al comarcal) y, principalmente, garantizar el control del Estado sobre las Administraciones locales, limitado formalmente a un control de legalidad a posteriori. Solamente merece destacarse, por su originalidad, la figura del «canciller de justicia» estonio, autoridad independiente elegida por el Parlamento y encargada de velar por el cumplimiento de la legalidad, no sólo por parte de las autoridades locales, sino también de las estatales, y que obtiene su inspiración y naturaleza de la antigua figura del canciller de justicia finlandés y del procurador ruso.

A pesar de la falta de entidades descentralizadas de nivel regional, condicionantes políticos derivados de la presencia de minorías étnicas organizadas en algunos de estos países puede ser una razón más que suficiente para desarrollar procesos de descentralización regional que consigan dar respuesta a las demandas de autogobierno por parte de tales minorías. La descentralización no es una finalidad en sí misma. Puede estar motivada por necesidades administrativas (racionalización de la gestión de servicios públicos y, en este sentido, mejora de su prestación) o por razones puramente políticas, sirviendo de respuesta a ciertas o potenciales tendencias centrifugas de minorías (étnicas, raciales, religiosas, lingüísticas, culturales) organizadas. Resulta, por tanto, sorprendente que los países considerados, algunos de ellos con fuerte presencia de grupos étnicos minoritarios, no hayan desarrollado fórmulas de descentralización que contribuyan a garantizar su estabilidad política. A modo de ejemplo, la presencia de la minoría húngara en Eslovaquia o Rumania, o la alemana en Chequia o Polonia, y sus demandas de autogobierno reclaman respuestas en materia de descentralización regional.

\section{Financiación y competencias de los entes territoriales descentralizados}

$\mathrm{Si}$, como se ha visto hasta ahora, la descentralización es una variable cuya concreción depende de numerosos factores, un 
buen indicador para medir el grado de descentralización alcanzado en un sistema político es el análisis de las finanzas regionales y locales en términos de gasto público consumido en relación con el gasto estatal, la relación entre las transferencias del Estado y los recursos propios o las características de los diferentes sistemas de financiación de los entes territoriales descentralizados. De todo ello se trata brevemente a continuación.

\section{A. Nivel de gasto y nivel de descentralización}

Con carácter general, el nivel de gasto público de los entes descentralizados es bajo y, en ocasiones, extremadamente bajo, salvo, quizá, en el caso de Hungría, donde pasa del 18,7\% del PNB y puede equipararse al nivel de gasto medio de un país occidental escasamente descentralizado. En alguna medida, el nivel de gasto de las Administraciones descentralizadas se corresponde con su techo competencial. Pero sólo en parte, puesto que este indicador no dice nada acerca del título con que una función concreta se ejerce por parte de la Administración local, ni con qué grado de autonomía. Puede conducir también a confusiones en países en transición, habida cuenta de que el sistema de financiación de los entes descentralizados propio de los regímenes socialistas puede estar parcialmente en vigor, y bajo estos regímenes las Administraciones territoriales descentralizadas son meros órganos del poder central encargados de ejecutar la parte del presupuesto estatal que va a dedicarse al ejercicio de funciones delegadas. Este escenario caracteriza al menos a Albania, Letonia y Lituania.

Por lo referido al montante del gasto público local, el principal factor de diferenciación viene dado por el hecho de que la Administración correspondiente tenga o no atribuida la competencia de educación. Así, los salarios de los maestros de las escuelas de enseñanza primaria corren a cuenta del presupuesto local en Hungría, Bulgaria, Albania, países bálticos y, desde 1996, en Polonia.

\section{B. La debilidad del poder fiscal de las haciendas locales}

Si la autonomía financiera en relación con el nivel de gasto tiende a aumentar, su evolución adquiere un mayor contraste comparándolo con los recursos de las haciendas locales. Polonia es el único país donde los recursos financieros de las Administraciones descentralizadas procedentes de ingresos fiscales es importante, representando el $24 \%$ de los recursos totales. Las subvenciones y transferencias procedentes del Estado representan, según los países, entre el 25 y el $50 \%$ de los recursos totales de las Administraciones locales, mientras que la participación en impuestos del Estado representan entre un cuarto y un tercio del total de los recursos. Mientras que en Albania las transferencias estatales representan el $84 \%$ de los recursos de los presupuestos locales, y el $62 \%$ en Letonia, pero solamente el 9\% en Lituania y el 20,4\% en Estonia, el grado de participación en los impuestos del Estado se invierte. Si sumamos las transferencias propiamente dichas y las participaciones en los impuestos del Estado, esta cantidad de recursos supone conjuntamente más del $50 \%$ de media de los recursos totales. Ahora bien, este porcentaje se dispara si se contempla la situación de los países menos «occidentalizados» en términos políticos y económicos: $84 \%$ en Bulgaria, $76,8 \%$ en Rumania, $96 \%$ en Albania, más del $95 \%$ en Lituania, y más del $98 \%$ en Letonia y Estonia.

Estos datos ponen de manifiesto, con independencia de la forma adoptada, la extrema dependencia financiera de las Administraciones locales con respecto a la Administración del Estado.

\section{El nivel competencial de las Administraciones locales}

Pueden distinguirse dos modelos de Administración local en Europa central y oriental si se toma como criterio de clasificación las competencias atribuidas a las Administraciones locales:

El primero de estos modelos estaría representado por Hungría y Bulgaria, donde las Administraciones locales procuran la mayoría de los servicios públicos a la población. Con relación al régimen socialista no hay apenas diferencias sobre la naturaleza de las competencias que corresponden a las Corporaciones locales; la auténtica diferencia, y verdaderamente esencial, con respecto al régimen anterior responde al hecho de que tales competencias son ejercidas por Corporaciones cuya autonomía está garantizada por la Constitución y el ordenamiento jurídico ${ }^{4}$.

El segundo de los modelos, propio más bien de Polonia, Chequia y Eslovaquia, consiste en que los servicios esenciales continúan siendo asumidos por la Administración del Estado, mejor dicho, por Administraciones desconcentradas territorialmente subordinadas el poder central, aunque, en ocasiones, establecen relaciones de cooperación con las Administraciones locales. En este modelo, y a diferencia del anterior, las dotaciones presupuestarias del Estado ocupan un lugar menos importante en relación con los recursos totales.

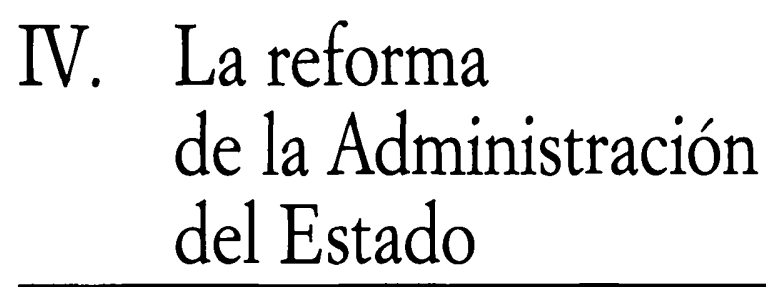

Así como la creación de niveles subnacionales de autogobierno es un fenómeno generalizado en todos los países post-so- 
cialistas que ha sido manifestación y motor a un tiempo de las reformas democratizadoras de estos países, las Administraciones estatales se caracterizan, si hablamos en términos generales por ser organizaciones fragmentadas, extremadamente politizadas y marcadas por acusaciones de corrupción derivada en buena parte de la falta de expectativas de promoción y de remuneración suficientes de su funcionariado. Los informes de la Comisión sobre las demandas de adhesión a la Unión Europea en alguno de estos países puede servir de indicador del estado de la cuestión. Si, además, recurrimos a los escasos trabajos académicos en la materia ${ }^{5}$, llegaremos a la conclusión de que el ingente volumen de proyectos legislativos de reforma de las Administraciones nacionales no son más que el reflejo del fracaso político en la creación de un sistema de función pública profesionalizado, de mecanismos de integración horizontal y del desarrollo de capacidades administrativas generales y de sistemas de control que pongan fin a la sensación de corrupción generalizada. Efectivamente, la adopción de estrategias de reforma de la Administración nacional de la mayor parte de los países que aspiran a formar parte de la Unión Europea ha consistido principalmente en una intensísima actividad legislativa sin resultados tangibles. VERHEIEN y COOMBES ${ }^{6}$ presentan un estudio comparado que trata de explicar el fracaso de los proyectos de reforma de las Administraciones de la Europa post-socialista mediante el empleo de una serie de factores que, a la luz de la experiencia de los países de Europa occidental, ejercen una influencia negativa. Parafraseando a estos autores, estos factores pueden son:

- El desinterés por parte de los responsables políticos de los proyectos de reforma que no arrojan dividendos en forma de votos.

- La implantación de iniciativas de reforma sin reflexión previa y sin evaluación suficiente de su factibilidad.

- La aplicación de medidas sin considerar el contexto politico y cultural.

- La aplicación de proyectos de reforma en condiciones de inestabilidad política que impida la obtención de resultados a largo plazo.

— La falta de adhesión de los funcionarios a las medidas de reforma.

- La falta de adaptación de los proyectos a las condiciones locales particulares.

Con independencia de que alguno de estos factores abstractos haya tenido algún grado de influencia en el fracaso de las reformas de los sucesivos proyectos de reforma de la Administración pública de los países considerados, hay a nuestro juicio varios elementos cuyo peso no cabe soslayar:

a) Por una parte, el obsesivo recurso a los instrumentos puramente jurídicos es netamente insuficiente como factor transformador cuando no va acompañado de actuaciones capaces de cambiar la «cultura política» vigente durante cuatro decenios. No hace falta decir que la eficacia de los instrumentos formales sólo puede evaluarse tras su efectiva aplicación, y de acuerdo con su espíritu. La búsqueda de la legitimidad por la ley, favorecida por la importancia atribuida por la Unión Europea a los aspectos jurídicos de las condiciones de adhesión no ha hecho más que favorecer una concepción legalista de la reforma burocrática.

b) Parece evidente que las medidas de reforma precisan de cierta continuidad para arrojar resultados. Pues bien, si se atiende a la estabilidad de los gobiernos y a los sistemas políticos de los países postsocialistas, éstos se caracterizan por un alto grado de polarización política y por rápidos cambios de gobierno. Resulta curioso cómo esta discontinuidad apenas afecta a las políticas económicas como al cambio administrativo. La consecuencia es que no hay políticas a largo plazo de reforma administrativa.

c) Sin embargo, quizá un factor que ha dificultado en gran medida las iniciativas de cambio administrativo ha sido la falta de conocimiento de la verdadera naturaleza de las Administraciones que se trata de reformar. Desde luego que un amplio proceso de reforma a largo plazo requiere de estabilidad política y de recursos económicos suficientes (que algunos países no pueden garantizar), pero también de un acertado diagnóstico de la situación de partida y de una clara definición de las metas que se trata de alcanzar. Pues bien, el problema de la reforma administrativa de los países post-socialistas debe contemplarse en un contexto mucho más amplio que supera a los meros enfoques jurídicos y técnico-gerenciales. El cambio en el status y las funciones de la burocracia debe hacerse relacionándolo con los aspectos globales de configuración del Estado y de la institucionalización de gobiernos democráticos. En otros términos, esta materia debe imbricarse estrechamente con la con. sideración del problema constitucional básico de la relación entre las ramas del poder y los mecanismos de suma y de articulación de intereses. El caso de Europa central y oriental no es tan sólo un problema de cambio o de transición entre regímenes políticos porque afecta al cambio de sistema económico.

El economista húngaro Janos KORNAI relata cómo resultaba común hablar de «miembros del aparato», «funcionarios» 0 «cuadros» en un sentido amplio, sin determinar dónde se ejercía una función concreta (en el partido o en el Estado), lo que justifica que algunos autores se refirieran al «Estado-partido»? En efecto, el error consiste en la aplicación de medidas de reforma para la que no puede ser reformado, sino sustituido en su totalidad. El tipo de interrelación partido-burocracia era extremadamente complejo, eran partes indiferenciables de un todo. El partido comunista no sólo desempeñaba un papel de socialización, sino también de coordinación y de consenso a través de la burocracia. El propio KORNAI reconoce a la coordinación burocrática como el más importante de los mecanismos de coordinación en el socialismo real. Ahora bien, tras el colapso de los partidos comunistas y el cambio de régimen, la Administración se ha reforzado. En las democracias occidentales la Administración es solamente un tipo de actor político 
que participa en el juego político junto a otros grupos de presión. En Occidente hay también formas distintas de agregación de intereses al margen del Estado, mientras que en los países post-socialistas sus organizaciones burocráticas fueron, y continúan siéndolo, las principales vías de agregación y articulación de intereses, el grupo de presión más fuerte y cohesionado.

En definitiva, los empeños de organizaciones exteriores (principalmente, la Unión Europea) en consolidar Administraciones estables, profesionalizadas y neutrales están condenados al fracaso si no consideran la naturaleza de la Administración. La consideración de la Administración como una maquinaria neutral, susceptible de ser «reformada» sin tomar en consideración su dimensión política (y la naturaleza esencialmente política de la burocracia de los regímenes socialistas) es una ficción que conduce a su transformación formal sin modificar la estructura de poder, fomentando la identificación del político y de quienes son designados por él con la organización que dirigen más que con la ideología que representan.
* Universidad Complutense de Madrid.

1 Este trabajo se basa en los datos proporcionados por el estudio publicado por la OCDE: MARCou (dir.), State Budget Support to Local Governments. A Report for the SIGMA Programme, Paris: OCDE, 1994; Marcou y BerebelYI (dirs.), New Trends in Local Govermment in Westem and Eastem Europe, Bruselas: Instituto Internacional de Ciencias Administrativas, 1993; Preparing Public Administration for the European Administrative Space, París: OCDE, SIGMA, 1998; en los datos proporcionados por la publicación de la Comisión Europea titulado Los Municipios y Europa, Luxemburgo: Oficina de Publicaciones Oficiales de la Unión Europea, 1997; y en los informes de la Comisión Europea sobre las solicitudes de adhesión a la Unión, de julio de 1997 y noviembre de 1998.

2 Sobre esta cuestión resulta interesante la contribución de WOLLMANN, «Varia. tionen institutionneller Transformation in sozialistischen Ländern: die (Wieder-) Einführung der kommunalen Selbstverwaltung in Ostdeutschland, Ungarn, Polen und Russland», en Wollmann, WIESEnTHAl y Bonker (dirs.), Transformation sozialistischer Gesellschaften: am Ende des Anfangs, Opladen: Leviathan-Sonderband, 1995.

${ }^{3}$ Algún autor se refiere a este hecho denominándolo «recentralización». Ver $\mathrm{H}$. WOLLMANN, «Institution building and decentralization in formerly socialist countries: the cases of Poland, Hungary and East Germany», en Government and Policy, No. 15, 1997.

- Tal como prevé la Constitución checa, y después de la Ley de diciembre de 1997 , se crearon 13 regiones desde enero del año 2000, aunque la estructura y competencias de los nuevos gobiernos regionales quedan por definir $y$, por lo tanto, resulta prematuro conocer su carácter autónomo. Por otra parte, las ciudades de Pragn, Brno, Ostrava y Plze tienen un estatuto especial.

' Las ciudades de Bratislava y Kosice tienen un estatuto especial.

${ }^{6}$ Estos municipios se dividen en 47 ciudades y 208 municipios rurales.

7 De estos municipios, 206 se consideran ciudades, de las que las mayores de 50.000 habitantes tienen estatuto de condado.
${ }^{8}$ Estos municipios se dividen en 69 ciudades y 492 municipios rurales. Hay, además, 7 llamadas «ciudades republicanas» (Riga, Jurmala, Jelgava, Liepaja, Ventspils, Rezenke y Daugavpils) que combinan los dos niveles de gobierno local.

9850 municipios tienen estatuto de ciudad. 65 de los 373 condados son ciudades con competencias en el ámbito del condado.

${ }^{10}$ Ver Wisla SURAzSKA, «Local revolutions in central Europe, 1990 to 1994: memoirs of mayors and councilors from Poland, Slovakia and the Czech Republic», en Publius, No. 2, 1996.

"Para un mayor detalle sobre este punto, puede verse: José M. RuANo, «Organización y gestión en las Administraciones locales de Europa occidental», en Revista Valenciana d'Estudis Autonòmics, No. 17, septiembre-diciembre 1996.

${ }^{12}$ Ver BIRD, EBel y Wawuch (dirs.), Decentralization of the Socialist States, Washington: Banco Mundial, 1995.

${ }^{13}$ Ver J. J. HESSE, «From transformation to modernization: administrative change in Central and Eastern Europe», en Public Administration, vol. 71, 1993; «Rebuilding the State. Administrative reform in Central and Eastern Europe», en Preparing Public Administration for the European Administrative Space, París: OCDE, SIGMA, 1998; T. Verhenen y D. CoOMBEs, Innovations in Public Management. Experiences from East and West Europe, Aldershot: Edward Elgar Publishers, 1998; J. Jabes y M. Vintar (eds.), Public Administration in transition, Bratislava: NISPAcee, 1996; J. JABES, Professionalisation of Public Servants in Central and Eas. term Europe, Bratislava: NISPAcee, 1998; T. VERHEJJEN, «Dix ans de réformes en Europe centrale et orientale: toujours les mêmes problèmes?», en Revue Française d'Administration Publique, No. 87, julio-septiembre 1998.

${ }^{14}$ T. VerheIJen y D. COOMBES, op. cit.

15 J. KORNA, The socialist system: the political economy of communism, Princeton University Press, 1992, p. 39.
BAI.CEROWICZ, L. (1994), Understanding postcommunists transitions, Joumal of Democracy, octubre.

Baldersheim, H.; OffFerdal, M.; Rose, A., y Swtaniewicz, P. (eds.) (1996), Local democracy and the process of transformation in East-Central Europe, Boulder: Westwiew Press.

Benz, A., y Goetz, K. H. (eds.) (1996), A new German Public Sector?, Alsershot: Hants.
BIRD, EBEL y WaLuch (dirs.) (1995), Decentralization of the Socialist States, Was. hington: Banco Mundial.

Commisssion reports on progress towards accession by Poland, Czech Republic, Slovakia, Hungary (julio de 1997 y noviembre de 1998).

Coulson, A. (ed.) (1995), Local governement in Eastem Europe, Aldershot: Hants.

Gabriellan, V. (1999), «Post-communist bureaucracies: organizational modes of transition», International Joumal of Public Administration, No. 1. 
GarbHer, G., y StarK, D. (eds.) (1997), Restructuring networks in post-socialism, Oxford: Oxford Press.

HESSE, J. J. (1993), «From transformation to modernization: administrative change in Central and Eastern Europe», en Public Administration, vol. 71.

- (1998), «Rebuilding the State. Administrative reform in Central and Eastern Europe», en Preparing Public Administration for the European Administrative Space, Paris: OCDE, SIGMA.

LLNER, M. (1997), «Territorial decentralisation - a stumbling block of democratic reforms in East Central Europe», Polish Sociological Review, No. 1.

JABES, J., y VINTAR, M. (eds.) (1996), Public Administration in transition, Bratislava: NISPAcee.

KöNIG, K. (1993), «Bureaucratic integration by elite transfer: the case of former GDR», Governance, julio.

Kornal, J. (1992), The socialist system: the political economy of communism, Princeton University Press.

Marcou (dir.) (1994), State Budget Support to Local Govemments. A Report for the SIGMA Programme, París: OCDE.

Marcou y Berebely (dirs.) (1993), New Trends in Local Govermment in Westem and Eastem Europe, Bruselas: Instituto Internacional de Ciencias Administrativas.

Szablovsk, G. J., y Deruen,.H. U. (eds.) (1993), «Special issue on regime transitions, elites and bureaucracies in Eastern Europe», Governance, julio.
SZALAI, J. (1998), Public opinion surveys as inputs to administrative reform in Hungary, París: SIGMA, OCDE.

SURAzSKA, Wisla (1996), «Local revolutions in central Europe, 1990 to 1994: memoirs of mayors and councilors from Poland, Slovakia and the Czech Republic», en Publius, No. 2.

Vanags, E.; Balanoff, H. R., y Lauletta, J. F. (1999), «After the fall of the Soviet Union: the changing status of local governments in the Republic of Latvia», International Joumal of Public Administration, No. 1.

Verhejen, T., y CoOmbes, D. (1998), Innovations in Public Management. Experiences from East and West Europe, Aldershot: Edward Elgar Publishers.

VerHeten, T. (1998), «Dix ans de réformes en Europe centrale et orientale: toujours les mêmes problèmes?», en Revue Française d'Administration Publique, No. 87, julio-septiembre.

Von Beyme, Klaus (1993), «Regime transitions and recruitment of elites in Eastern Europe», Governance, julio.

Wollmann, H. (1997), «Institution building and decentralization in formerly socialist countries: the cases of Poland, Hungary and East Germany», en Govemment and Policy, No. 15.

Wolmann, WIESENTHAL y BonkER (dirs.) (1995), Transformation sozialistischer Gesellschaften: am Ende des Anfangs, Opladen: Leviathan-Sonderband. 